\title{
Moderate concentrations of supplemental oxygen worsen hypercapnia in obesity hypoventilation syndrome: a randomised crossover study
}

\author{
Carly Ann Hollier, ${ }^{1,2}$ Alison Rosemary Harmer, ${ }^{2}$ Lyndal Jane Maxwell, ${ }^{3}$ \\ Collette Menadue, ${ }^{1}$ Grant Neville Willson, ${ }^{4}$ Gunnar Unger, ${ }^{5}$ Daniel Flunt, ${ }^{1}$ \\ Deborah Ann Black, ${ }^{2}$ Amanda Jane Piper ${ }^{1,5}$
}

\begin{abstract}
- Additional material is published online only. To view please visit the journal online (http://dx.doi.org/10.1136/ thoraxjn-2013-204389).

${ }^{1}$ Department of Respiratory and Sleep Medicine, Royal Prince Alfred Hospital, Camperdown, New South Wales, Australia

${ }^{2}$ Faculty of Health Sciences, University of Sydney, Lidcombe, New South Wales, Australia ${ }^{3}$ Faculty of Health Sciences, Australian Catholic University, North Sydney, New South

Wales, Australia

${ }^{4}$ Faculty of Health, University of Canberra, Bruce, Australian Capital Territory, Australia ${ }^{5}$ Woolcock Institute of Medical Research, University of Sydney, Glebe, New South Wales, Australia
\end{abstract}

\section{Correspondence to} Carly Ann Hollier, Department of Respiratory and Sleep Medicine, Royal Prince Alfred Hospital, Sleep Unit, Level 11, Building 75, Royal Prince Alfred Hospital, Missenden Rd, Camperdown, NSW 2050, Australia; carly.hollier@sswahs. nsw.gov.au

Received 19 August 2013 Revised 24 October 2013 Accepted 31 October 2013 Published Online First 19 November 2013

\footnotetext{
To cite: Hollier CA, Harmer AR, Maxwell L, et al. Thorax 2014;69: 346-353.
}

\begin{abstract}
Introduction In people with obesity hypoventilation

syndrome (OHS), breathing 100\% oxygen increases

carbon dioxide $\left(\mathrm{PCO}_{2}\right)$, but its effect on $\mathrm{pH}$ is unknown.

This study investigated the effects of moderate

concentrations of supplemental oxygen on $\mathrm{PCO}_{2}, \mathrm{pH}$,

minute ventilation $\left(V_{E}\right)$ and physiological dead space to

tidal volume ratio $\left(V_{D} / V_{T}\right)$ among people with stable

untreated OHS, with comparison to healthy controls.

Methods In a double-blind randomised crossover

study, participants breathed oxygen concentrations $\left(\mathrm{F}_{i} \mathrm{O}_{2}\right)$

0.28 and 0.50 , each for $20 \mathrm{~min}$, separated by a $45 \mathrm{~min}$

washout period. Arterialised-venous $\mathrm{PCO}_{2}\left(\mathrm{PavCO}_{2}\right)$ and

$\mathrm{pH}, \mathrm{V}_{\mathrm{E}}$ and $\mathrm{V}_{\mathrm{D}} / \mathrm{V}_{\mathrm{T}}$ were measured at baseline, then every

5 min. Data were analysed using general linear model analysis.
\end{abstract}

Results 28 participants were recruited (14 OHS, 14 controls). Among OHS participants (mean $\pm \mathrm{SD}$ arterial $\mathrm{PCO}_{2} 6.7 \pm 0.5 \mathrm{kPa}$; arterial oxygen $8.9 \pm 1.4 \mathrm{kPa}$ ) $\mathrm{F}_{i} \mathrm{O}_{2}$ 0.28 and 0.50 maintained oxygen saturation $98-100 \%$. After 20 min of $\mathrm{F}_{\mathrm{i}} \mathrm{O}_{2} 0.28$, PavCO 2 change $\left(\triangle \mathrm{PavCO}_{2}\right)$ was $0.3 \pm 0.2 \mathrm{kPa}(p=0.013)$, with minimal change in $V_{E}$ and rises in $V_{D} / V_{T}$ of $1 \pm 5 \%(p=0.012) . F_{i} O_{2} 0.50$ increased $\mathrm{PavCO}_{2}$ by $0.5 \pm 0.4 \mathrm{kPa}(\mathrm{p}=0.012)$, induced acidaemia and increased $V_{D} / V_{T}$ by $3 \pm 3 \%(p=0.012)$. $V_{E}$ fell by $1.2 \pm 2.1 \mathrm{~L} / \mathrm{min}$ within $5 \mathrm{~min}$ then recovered individually to varying degrees. A negative correlation between $\Delta \mathrm{V}_{\mathrm{E}}$ and $\Delta \mathrm{PavCO}_{2}(\mathrm{r}=-0.60, \mathrm{p}=0.024)$ suggested that ventilatory responses were the key determinant of $\mathrm{PavCO}_{2}$ rises. Among controls, $\mathrm{F}_{i} \mathrm{O}_{2} 0.28$ and 0.50 did not change $\mathrm{PavCO}_{2}$ or $\mathrm{pH}$, but $\mathrm{F}_{\mathrm{i}} \mathrm{O}_{2} 0.50$ significantly increased $\mathrm{V}_{\mathrm{E}}$ and $\mathrm{V}_{\mathrm{D}} / \mathrm{V}_{\mathrm{T}}$.

Conclusion Commonly used oxygen concentrations caused hypoventilation, $\mathrm{PavCO}_{2}$ rises and acidaemia among people with stable OHS. This highlights the potential dangers of this common intervention in this group.

\section{INTRODUCTION}

In obesity hypoventilation syndrome (OHS), chronic hypercapnia develops as a consequence of obesity. This condition is associated with alveolar hypoventilation, restricted pulmonary function, severe sleep-disordered breathing and higher rates of morbidity, mortality and healthcare costs compared with eucapnic obesity. ${ }^{1-4}$ OHS affects approximately $0.15-0.3 \%$ of the US population and over $50 \%$ of hospital inpatients with body
Key messages

What is the key question?

- What are the effects of moderate concentrations of supplemental oxygen on $\mathrm{CO}_{2}, \mathrm{pH}$, ventilation and physiological dead space to tidal volume ratio $\left(V_{D} / N_{T}\right)$ in people with obesity hypoventilation syndrome (OHS)?

\section{What is the bottom line?}

- In $\mathrm{OHS}$, breathing moderate concentration supplemental oxygen for 20 min worsened hypercapnia and induced acidaemia due to hypoventilation and a worsening of $V_{D} / N_{T}$.

\section{Why read on?}

- This is the first study to evaluate the effects of moderate concentration supplemental oxygen on blood gases and respiratory variables in $\mathrm{OHS}$ and highlights the potential risks of this common intervention among this unique population.

mass index $(\mathrm{BMI})>50 \mathrm{~kg} / \mathrm{m}^{2}{ }^{1}$ Despite this, OHS frequently goes undiagnosed among hospital inpatients with obesity. ${ }^{1}$

Supplemental oxygen is a common medical intervention ${ }^{6}$ and may be administered to patients with $\mathrm{OHS}$ in a range of healthcare settings. British Thoracic Society guidelines on emergency oxygen prescription identify patients with OHS as a group among whom excessive concentrations of supplemental oxygen, causing hyperoxia, could increase carbon dioxide $\left(\mathrm{CO}_{2}\right)$ levels and lower $\mathrm{pH} .{ }^{6}$ The basis of the guidelines relies upon expert opinion and data from COPD, because very few studies have investigated the effects of supplemental oxygen in OHS. Among patients with obesity and elevated transcutaneous $\mathrm{CO}_{2}$ pressure $\left(\mathrm{PCO}_{2}\right)$, breathing $100 \%$ oxygen induced an average rise in transcutaneous $\mathrm{PCO}_{2}$ of $0.7 \mathrm{kPa}$ (with rises of $>1.3 \mathrm{kPa}$ in three patients). ${ }^{7}$ However, the effect of oxygen on $\mathrm{pH}$, an important prognostic indicator, ${ }^{2} 89$ was not reported. Furthermore, 100\% oxygen is rarely used in clinical practice. ${ }^{7}$ Hence, the clinical relevance of these data is uncertain.

During acute exacerbations of COPD, hyperoxia arising from supplemental oxygen worsens hypercapnia and $\mathrm{pH}$, and has been linked to more 
frequent admission to intensive care and increased hospital length of stay and mortality. ${ }^{9-11}$ Hyperoxia-induced hypercapnia in COPD has been attributed to increased ventilation/perfusion (V/Q) inequality, mediated by the reversal of hypoxic vasoconstriction ${ }^{12-14}$; however recent evidence suggests that hypoventilation may be a quantitatively more important mechanism. ${ }^{15} 16$ Whether or not these mechanisms apply to OHS, which has a vastly different pathophysiology to COPD, has yet to be determined.

The aims of the present study were to document the time course of changes in $\mathrm{PCO}_{2}, \mathrm{pH}$ and respiratory variables in response to clinically relevant, moderate concentrations of supplemental oxygen among people with OHS in comparison to a healthy control group; and to examine physiological mechanisms that may explain any oxygen-induced changes in $\mathrm{PCO}_{2}$.

\section{METHODS}

Written informed consent was obtained from all participants. The study was approved by the Ethics Committees of Royal Prince Alfred Hospital (protocol no. X12-0067 and HREC/12/ $\mathrm{RPAH} / 109$ ) and the University of Sydney (Ref. 14935) and registered on the Australian and New Zealand Clinical Trials Registry (ACTRN1260800172303).

\section{Participants}

Patients referred to the Sleep Unit, Royal Prince Alfred Hospital with obesity and possible hypercapnia were screened for eligibility. Inclusion criteria were the combination of obesity $(\mathrm{BMI} \geq$ $\left.30 \mathrm{~kg} / \mathrm{m}^{2}\right)$ and daytime hypercapnia (arterial $\mathrm{PCO}_{2}\left(\mathrm{PaCO}_{2}\right)>$ $6 \mathrm{kPa}$ ). Patients were excluded in the case of any other potential cause of hypercapnia, current use of positive airway pressure, acute respiratory/cardiac illness within the previous month, acidaemia or psychiatric illness. A control group was recruited concurrently from a sample of convenience. Each control participant was age ( \pm 3 years) and gender matched with an

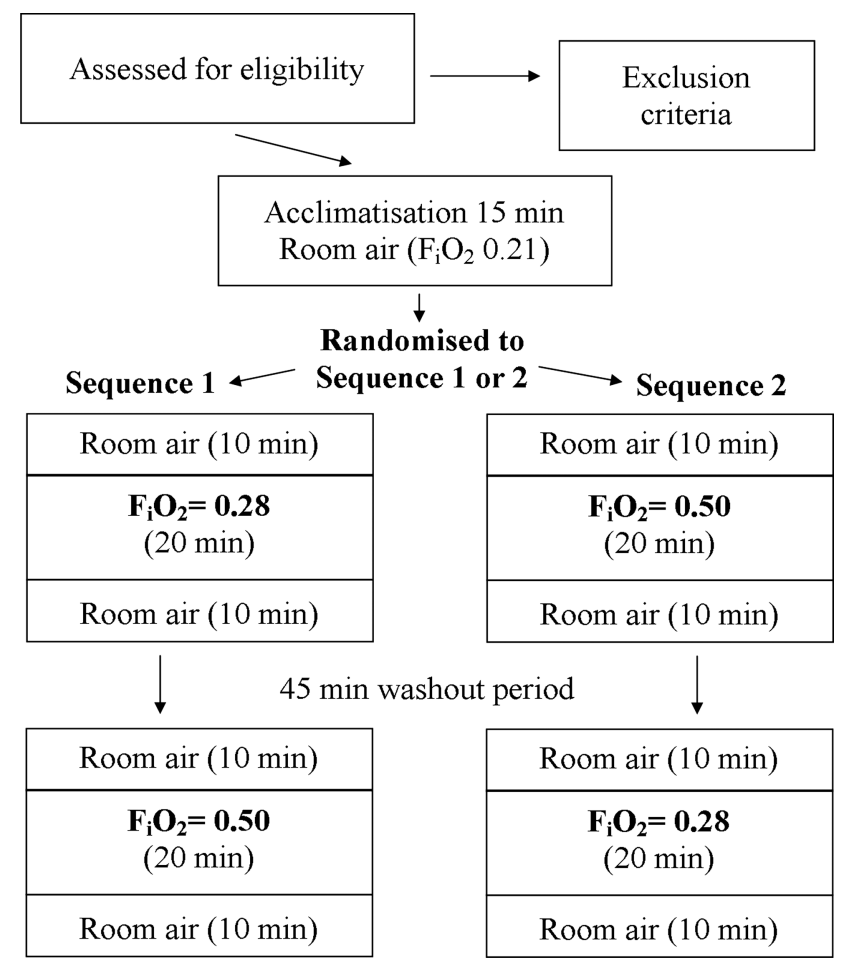

Figure 1 Study design. $\mathrm{F}_{\mathrm{i}} \mathrm{O}_{2}$, inspired oxygen fraction.
OHS participant, non-smoking, with $\mathrm{BMI}<30 \mathrm{~kg} / \mathrm{m}^{2}$, normal spirometry and no history of cardiorespiratory disease.

\section{Study design and protocol}

Using a double-blind randomised crossover design (figure 1), each participant breathed two fractions of inspired oxygen $\left(\mathrm{F}_{\mathrm{i}} \mathrm{O}_{2}\right) 0.28$ and 0.50 in random order (sequence 1 or 2 ), via a breathing circuit, after a circuit acclimatisation period. Each test began with a $10 \mathrm{~min}$ period of breathing room air via the circuit (baseline), followed by a $20 \mathrm{~min}$ period of supplemental oxygen $\left(\mathrm{F}_{\mathrm{i}} \mathrm{O}_{2} 0.28\right.$ or 0.50$)$, and then a $10 \mathrm{~min}$ period of breathing room air (recovery). A $45 \mathrm{~min}$ washout period separated the two supplemental oxygen tests.

Randomisation of sequence was generated using an online randomisation programme (http://www.randomization.com), with allocation concealed via sealed opaque envelopes. The chief investigator and participants remained blinded throughout. An unblinded coinvestigator operated equipment and instructed participants. Testing began between 8:30am and 10:00am. All participants had fasted and abstained from caffeine from midnight.

\section{Instrumentation}

The closed breathing circuit comprised a dry rolling-seal spirometer, a bias-flow generator, a soda-lime $\mathrm{CO}_{2}$ absorber and a T-connector at the participant interface. Gas was continuously sampled at the interface using oxygen $/ \mathrm{CO}_{2}$ sensors. A stable $\mathrm{F}_{\mathrm{i}} \mathrm{O}_{2}$ was maintained through titration of bottled air and oxygen using continuous real-time feedback from the oxygen sensor. Immediately after each $\mathrm{F}_{\mathrm{i}} \mathrm{O}_{2}$ change, the circuit was flushed to allow stabilisation at the new $\mathrm{F}_{\mathrm{i}} \mathrm{O}_{2}$ within 2 min. Participants breathed through the circuit via a nasal mask (dead space $175 \mathrm{~mL})$ with the mouth closed $(\mathrm{n}=25)$, or in the case of nasal obstruction, via a mouthpiece (dead space $100 \mathrm{~mL}$ ) with a nose peg $(n=3)$.

\section{Outcome measures}

On the day of testing, baseline measures of height, weight, spirometry and arterial blood gases (ABGs) were performed.

Arterialised-venous blood was repeatedly sampled to obtain surrogate measures of arterial $\mathrm{PCO}_{2}\left(\mathrm{PavCO}_{2}\right)$ and $\mathrm{pH}$. We previously described and validated this method in OHS. ${ }^{17} \mathrm{An}$ oximeter continuously measured pulse oxygen saturation $\left(\mathrm{SpO}_{2}\right)$ (Radical, Masimo, Irvine, California, USA). Signals from the oxygen $/ \mathrm{CO}_{2}$ sensors and spirometer were recorded by a computer programme and used to derive and/or display breath-by-breath minute ventilation $\left(\mathrm{V}_{\mathrm{E}}\right)$, tidal volume $\left(\mathrm{V}_{\mathrm{T}}\right)$ and respiratory rate (RR). Breath-by-breath physiological dead space

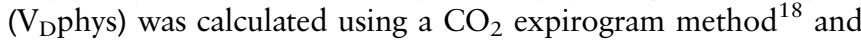
adjusted by subtracting apparatus dead space, then divided by $\mathrm{V}_{\mathrm{T}}$ to obtain $\mathrm{V}_{\mathrm{D}}$ phys to $\mathrm{V}_{\mathrm{T}}$ ratio $\left(\mathrm{V}_{\mathrm{D}} / \mathrm{V}_{\mathrm{T}}\right)$. Data affected by leak or artefact were systematically excluded. Subsequently, breath-by-breath data were averaged over $60 \mathrm{~s}$.

For final analysis, data obtained during the following periods were included: the final minute of the $10 \mathrm{~min}$ baseline, the final minute of each $5 \mathrm{~min}$ epoch of supplemental oxygen, and the final minute of the 10 min recovery. Arterialised-venous blood samples were drawn within the last $10 \mathrm{~s}$ of each of these periods.

\section{Statistical analysis}

Data are presented as mean $\pm \mathrm{SD}$ or median (IQR), and mean difference (MD) and 95\% CI for between-group comparisons. A significance level of $\mathrm{p}<0.05$ was used for all comparisons. Between-group MDs in baseline variables were compared using 
Figure 2 Flow diagram of enrolment, randomisation/allocation and analysis phases. OHS, obesity hypoventilation syndrome, PAP, positive airway pressure.

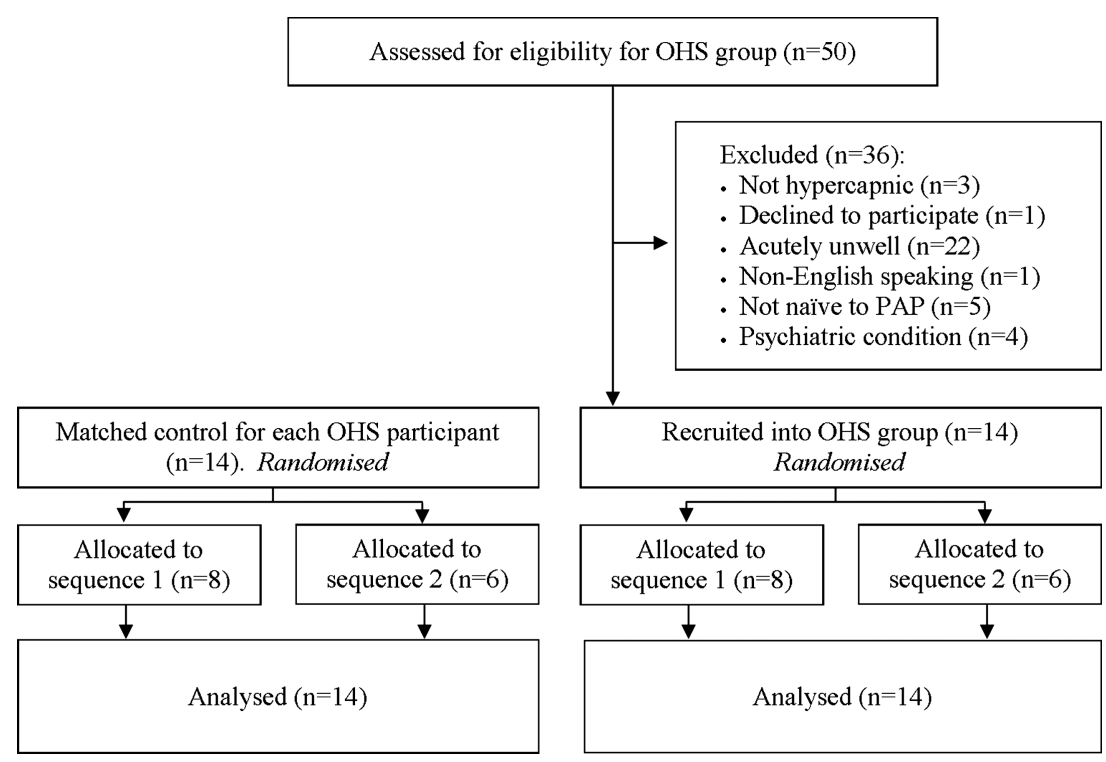

independent t-tests. General linear model (univariate, repeated measures) analysis compared responses to supplemental oxygen between participant groups (factor: group; factor interaction: time-by-group) for primary $\left(\mathrm{PavCO}_{2}\right)$ and secondary $\left(\mathrm{pH}, \mathrm{V}_{\mathrm{E}}\right.$ and $\mathrm{V}_{\mathrm{D}} / \mathrm{V}_{\mathrm{T}}$ ) outcomes; between baseline and supplemental oxygen (factor: time) for primary, secondary and tertiary $\left(\mathrm{V}_{\mathrm{T}}\right.$, $\mathrm{RR}, \mathrm{V}_{\mathrm{D}}$ Phys) outcomes; and between the two oxygen concentrations (factor: concentration) for $\mathrm{PavCO}_{2}$. For non-parametric data, the Friedman test was used to evaluate effects of time. To account for multiple comparisons the level of significance was adjusted (adj.p) using Holm's Bonferroni procedure. ${ }^{19}$ Within the OHS group only, Pearson's correlation coefficient was calculated to examine potential factors associated with the change in

Table 1 Participant characteristics, baseline arterial blood gases and spirometry

\begin{tabular}{|c|c|c|c|}
\hline & OHS & Controls & $p$ Value \\
\hline Age (years) & $48 \pm 12$ & $48 \pm 12$ & 0.987 \\
\hline Gender (F/M) & $3 / 11$ & $3 / 11$ & - \\
\hline BMI $\left(\mathrm{kg} / \mathrm{m}^{2}\right)$ & $53 \pm 7$ & $25 \pm 4$ & $<0.001$ \\
\hline Weight (kg) & $154 \pm 21$ & $73 \pm 15$ & $<0.001$ \\
\hline $\mathrm{pH}$ & $7.395 \pm 0.030$ & $7.414 \pm 0.019^{*}$ & 0.055 \\
\hline $\mathrm{PaCO}_{2}(\mathrm{kPa})$ & $6.7 \pm 0.5$ & $5.5 \pm 0.4^{*}$ & $<0.001$ \\
\hline $\mathrm{PaO}_{2}(\mathrm{kPa})$ & $8.9 \pm 1.4$ & $14.3 \pm 1.1^{*}$ & $<0.001$ \\
\hline $\mathrm{SaO}_{2}(\%)$ & $92 \pm 3$ & $98 \pm 1 *$ & $<0.001$ \\
\hline $\mathrm{HCO}_{3}^{-}(\mathrm{mmol} / \mathrm{L})$ & $30.3 \pm 1.7$ & $25.8 \pm 1.2^{*}$ & $<0.001$ \\
\hline $\mathrm{A}-\mathrm{aDO}_{2}(\mathrm{kPa})$ & $3.6 \pm 1.4$ & $0.9 \pm 1.2^{*}$ & $<0.001$ \\
\hline Haemoglobin ( $\mathrm{g} / \mathrm{L})$ & $153 \pm 20$ & $143 \pm 11$ & 0.156 \\
\hline $\mathrm{FEV}_{1}(\mathrm{~L})$ & $2.39 \pm 0.72$ & $3.71 \pm 0.71$ & 0.001 \\
\hline $\mathrm{FEV}_{1} \%$ predicted & $73 \pm 14$ & $106 \pm 11$ & $<0.001$ \\
\hline FVC (L) & $3.03 \pm 0.85$ & $4.54 \pm 0.77$ & $<0.001$ \\
\hline FVC $\%$ predicted & $77 \pm 14$ & $107 \pm 13$ & $<0.001$ \\
\hline $\mathrm{FEV}_{1} / \mathrm{FVC}(\%)$ & $79 \pm 6$ & $82 \pm 5$ & 0.231 \\
\hline
\end{tabular}

Data presented as mean $\pm S D ; p$ value represents two-tailed significance from independent $\mathrm{t}$ tests comparing control and OHS groups.

*Data reported from $n=13$, as arterial blood gas could not be performed in one control participant.

$\mathrm{A}-\mathrm{aDO}_{2}$, alveolar-arterial oxygen difference; $\mathrm{BMI}$, body mass index; $\mathrm{FEV}_{1}$, forced expired volume in $1 \mathrm{~s}$; FVC, forced vital capacity; $\mathrm{HCO}_{3}^{-}$, bicarbonate; $\mathrm{OHS}$, obesity hypoventilation syndrome; $\mathrm{PaCO}_{2}$, arterial partial pressure of $\mathrm{CO}_{2} ; \mathrm{PaO}_{2}$, arterial partial pressure of $\mathrm{O}_{2}$.
$\mathrm{PavCO}_{2}$ after 20 min $\left(\triangle \mathrm{PavCO}_{2}\right)$ of $\mathrm{F}_{\mathrm{i}} \mathrm{O}_{2} \quad 0.50$, including baseline $\mathrm{PaCO}_{2}$, bicarbonate $\left(\mathrm{HCO}_{3}^{-}\right)$and arterial oxygen saturation $\left(\mathrm{SaO}_{2}\right), \Delta \mathrm{V}_{\mathrm{E}}$, and $\Delta \mathrm{V}_{\mathrm{D}} / \mathrm{V}_{\mathrm{T}}$. The study was powered to detect a $\Delta \mathrm{PavCO}_{2}$ of $0.4 \mathrm{kPa}^{16}$ from baseline during supplemental oxygen within the OHS group, with an SD estimate of $0.45 \mathrm{kPa}$ (using data from the first five OHS participants), power of 0.8 , $\alpha$ of 0.05 . A sample of $14 \mathrm{OHS}$ participants (hence 14 matched controls) was required. Data were analysed using PASW 18 (IBM, Armonk, New York, USA).

\section{RESULTS}

Fourteen participants with OHS and 14 controls were recruited between August 2008 and February 2012 (figure 2). Baseline characteristics (table 1) show that groups were well matched for age and gender. Participants with OHS presented with superobesity, mild hypercapnia and hypoxaemia, and mild pulmonary restriction.

Table 2 shows all variables at baseline and after $20 \mathrm{~min}$ of breathing each oxygen concentration. In both groups, supplemental oxygen induced hyperoxia, with $\mathrm{SpO}_{2}$ in OHS increasing to $99 \pm 1 \%$ during $\mathrm{F}_{\mathrm{i}} \mathrm{O}_{2} 0.28$ and $100 \pm 0 \%$ during $\mathrm{F}_{\mathrm{i}} \mathrm{O}_{2}$ 0.50 . Figure 3 depicts time courses of $\mathrm{PavCO}_{2}, \mathrm{~V}_{\mathrm{E}}$ and $\mathrm{V}_{\mathrm{D}} / \mathrm{V}_{\mathrm{T}}$ There was no significant effect of test order on $\mathrm{PavCO}_{2}$ for either group. General linear model comparisons are detailed in table E1, online data supplement.

\section{Between-group comparisons}

Responses to supplemental oxygen were significantly different between groups for $\mathrm{PavCO}_{2}$ and $\mathrm{pH}$ (figure 3, table 3), but not for $\mathrm{V}_{\mathrm{E}}$ after adjustment. There were no significant between-group differences or interaction effects for $\mathrm{V}_{\mathrm{D}} / \mathrm{V}_{\mathrm{T}}$, hence data from both groups were combined to analyse the effects of time for $\mathrm{V}_{\mathrm{D}} / \mathrm{V}_{\mathrm{T}}$.

\section{OHS group: responses to supplemental oxygen}

Amongst $\mathrm{OHS}$ participants, significant increases in $\mathrm{PavCO}_{2}$ occurred after $20 \mathrm{~min}$ of $\mathrm{F}_{\mathrm{i}} \mathrm{O}_{2} 0.28(0.3 \pm 0.2 \mathrm{kPa}$, adj.p $=0.013)$ and $\mathrm{F}_{\mathrm{i}} \mathrm{O}_{2} 0.50(0.5 \pm 0.4 \mathrm{kPa}$, adj.p $=0.012)$ (table 2, figure 3$)$. Consequently, proportional changes in $\mathrm{pH}$ were observed, resulting in acidaemia after $20 \mathrm{~min}$ of $\mathrm{F}_{\mathrm{i}} \mathrm{O}_{2} 0.50 \quad(7.346 \pm 0.030$, adj. $\mathrm{p}=0.011)$. There was a significant difference in $\mathrm{PavCO}_{2}$ between the two oxygen concentrations, but this became nonsignificant after adjustment (raw $\mathrm{p}=0.021$, adj.p $=0.315$ ). 
Table 2 Physiological variables at baseline and at the end of $\mathrm{F}_{i} \mathrm{O}_{2} 0.28$ and $\mathrm{F}_{i} \mathrm{O}_{2} \quad 0.50$ tests

\begin{tabular}{|c|c|c|c|c|c|c|}
\hline & \multicolumn{3}{|l|}{$\mathrm{F}_{\mathrm{i}} \mathrm{O}_{2} 0.28$} & \multicolumn{3}{|l|}{$\mathrm{F}_{\mathrm{i}} \mathrm{O}_{2} 0.50$} \\
\hline & Room air baseline & $20 \mathrm{~min}$ & Adj. $p$ value & Room air baseline & $20 \mathrm{~min}$ & Adj. $p$ value \\
\hline \multicolumn{7}{|l|}{ OHS group } \\
\hline $\mathrm{SpO}_{2}(\%)$ & $94 \pm 3$ & $99 \pm 1$ & - & $94 \pm 3$ & $100 \pm 0$ & - \\
\hline $\mathrm{PavCO}_{2}(\mathrm{kPa})$ & $7.1 \pm 0.6$ & $7.4 \pm 0.6$ & 0.013 & $7.2 \pm 0.6$ & $7.7 \pm 1.0$ & 0.012 \\
\hline $\mathrm{pH}$ & $7.371 \pm 0.019$ & $7.359 \pm 0.027$ & $0.406^{*}$ & $7.373 \pm 0.021$ & $7.346 \pm 0.030$ & 0.011 \\
\hline $\mathrm{V}_{\mathrm{E}}(\mathrm{L} / \mathrm{min})$ & $9.9 \pm 2.3$ & $9.9 \pm 2.8$ & 0.997 & $9.6 \pm 2.1$ & $9.3 \pm 2.9$ & $0.224^{*}$ \\
\hline $\mathrm{V}_{\mathrm{D}} / \mathrm{V}_{\mathrm{T}}$ (ratio) & $0.28 \pm 0.05$ & $0.29 \pm 0.03$ & 0.012 & $0.29 \pm 0.05$ & $0.32 \pm 0.05$ & 0.012 \\
\hline $\mathrm{V}_{\mathrm{D}}$ phys (mL) & $200 \pm 55$ & $196 \pm 26$ & $>0.999$ & $194 \pm 56$ & $192 \pm 37$ & $>0.999$ \\
\hline $\mathrm{V}_{\mathrm{T}}(\mathrm{mL})$ & $633 \pm 149$ & $597 \pm 129$ & 0.012 & $578 \pm 105$ & $489 \pm 107$ & 0.012 \\
\hline RR (br/min) & $17.5 \pm 5.2$ & $18.2 \pm 4.7$ & $>0.999$ & $18.1 \pm 4.9$ & $18.1 \pm 4.2$ & $>0.999$ \\
\hline \multicolumn{7}{|l|}{ Control group } \\
\hline $\mathrm{SpO}_{2}(\%)$ & $98 \pm 1$ & $100 \pm 1$ & - & $98 \pm 1$ & $100 \pm 0$ & - \\
\hline $\mathrm{PavCO}_{2}(\mathrm{kPa})$ & $5.5 \pm 0.4$ & $5.6 \pm 0.2$ & 0.726 & $5.4 \pm 0.3$ & $5.4 \pm 0.4$ & $>0.999$ \\
\hline $\mathrm{pH}$ & $7.408 \pm 0.023$ & $7.397 \pm 0.010$ & $>0.999$ & $7.407 \pm 0.020$ & $7.407 \pm 0.023$ & $>0.999$ \\
\hline $\mathrm{V}_{\mathrm{E}}(\mathrm{L} / \mathrm{min})$ & $7.5 \pm 1.6$ & $7.5 \pm 1.7$ & $>0.999$ & $7.6 \pm 1.8$ & $8.6 \pm 1.9$ & 0.019 \\
\hline $\mathrm{V}_{\mathrm{D}} / \mathrm{V}_{\mathrm{T}}$ (ratio) & $0.27 \pm 0.05$ & $0.29 \pm 0.04$ & 0.012 & $0.28 \pm 0.04$ & $0.32 \pm 0.04$ & 0.012 \\
\hline$V_{D}$ phys (mL) & $232 \pm 79$ & $237 \pm 53$ & $0.085^{*}$ & $244 \pm 123$ & $263 \pm 97$ & $0.085^{*}$ \\
\hline $\mathrm{V}_{\mathrm{T}}(\mathrm{mL})$ & $813(353)$ & 754 (356) & $>0.999$ & $751(285)$ & $751(264)$ & $>0.999$ \\
\hline $\mathrm{RR}$ (br/min) & $10.3 \pm 4.2$ & $10.5 \pm 4.5$ & $0.195^{*}$ & $10.6 \pm 3.7$ & $11.8 \pm 3.6$ & $0.195^{*}$ \\
\hline
\end{tabular}

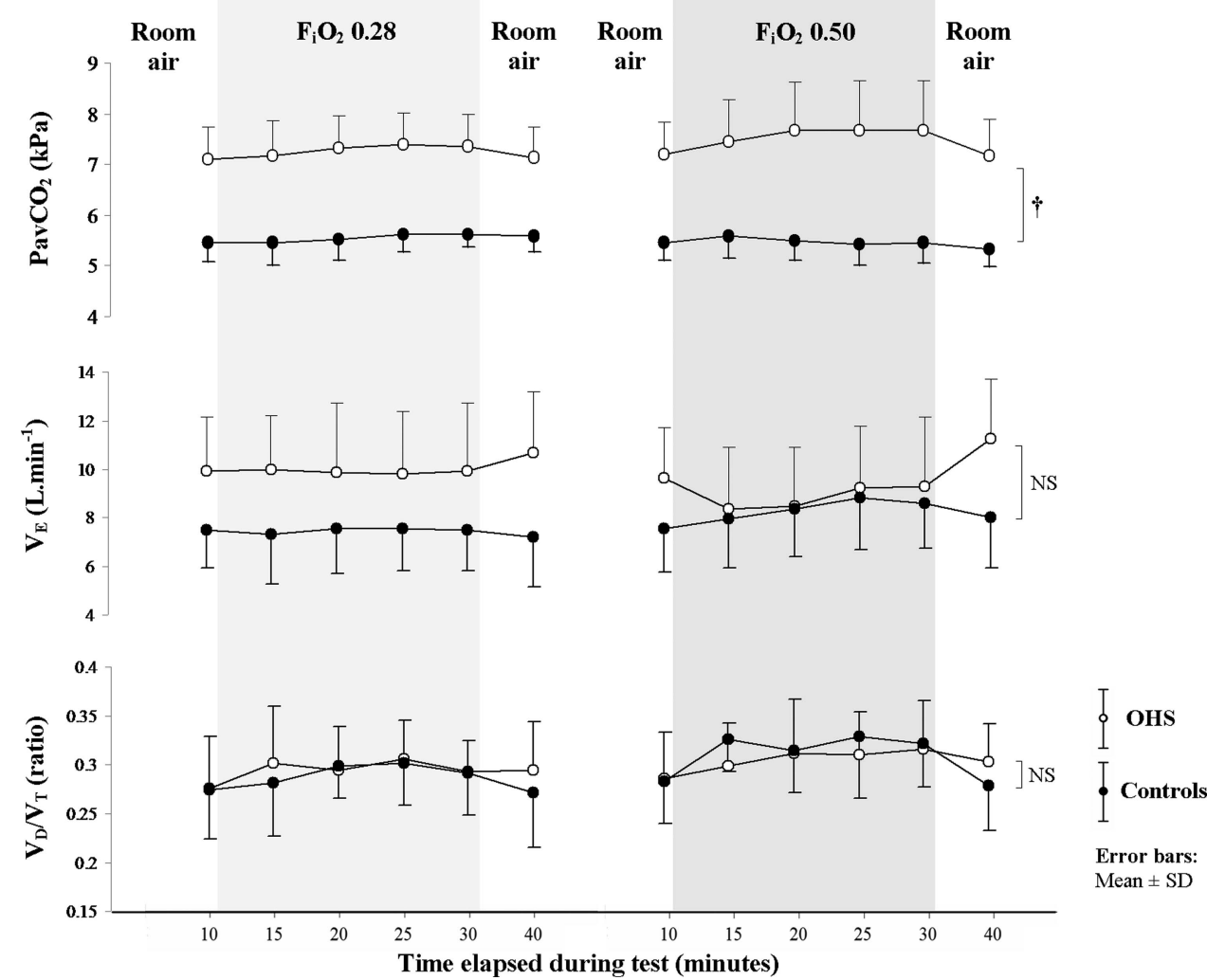

Figure 3 Time course of changes in $\mathrm{PavCO}_{2}, \mathrm{~V}_{\mathrm{E}}$ and $\mathrm{V}_{\mathrm{D}} / \mathrm{V}_{\mathrm{T}}$ during air/oxygen breathing tests for OHS group (open circles) and control group (closed circles), with results of general linear model analysis of between-group differences (factor: group, and group by time). †Adjusted $\mathrm{p}$ value $=0.01 ; \mathrm{F}_{\mathrm{i}} \mathrm{O}_{2}$, inspired oxygen fraction; $\mathrm{NS}$, non-significant; $\mathrm{OHS}$, obesity hypoventilation syndrome; $\mathrm{PavCO}_{2}$, arterialised-venous $\mathrm{CO}_{2}$; $V_{E}$, minute ventilation; $V_{D} / V_{T}$, dead space to tidal volume ratio. 
Table 3 Between-group comparisons of responses to supplemental oxygen

\begin{tabular}{|c|c|c|c|c|c|c|}
\hline & \multirow[b]{2}{*}{ MD $(\Delta \text { at } 20 \mathrm{~min})^{*}$} & \multirow[b]{2}{*}{$95 \% \mathrm{Cl}$} & \multicolumn{2}{|c|}{ Main effect: group } & \multicolumn{2}{|c|}{ Interaction: time by group } \\
\hline & & & Raw p value & Adj. $p$ value & Raw p value & Adj. $p$ value \\
\hline $\mathrm{PavCO}_{2}(\mathrm{kPa})$ & 0.31 & 0.13 to 0.49 & $<0.001$ & 0.010 & $<0.001$ & 0.014 \\
\hline $\mathrm{pH}$ & -0.014 & -0.023 to -0.005 & $<0.001$ & 0.011 & 0.001 & 0.019 \\
\hline $\mathrm{V}_{\mathrm{E}}(\mathrm{L} / \mathrm{min})$ & -0.8 & -1.3 to -0.38 & 0.045 & 0.585 & 0.051 & 0.612 \\
\hline $\mathrm{V}_{\mathrm{D}} / \mathrm{V}_{\mathrm{T}}$ (ratio) & 0.01 & -0.03 to 0.01 & 0.085 & 0.850 & 0.128 & $>0.999$ \\
\hline
\end{tabular}

There was a positive correlation between $\Delta \mathrm{PavCO}_{2} \quad\left(\mathrm{~F}_{\mathrm{i}} \mathrm{O}_{2}\right.$ $0.50)$ and $\mathrm{PaCO}_{2}(\mathrm{r}=0.60, \mathrm{p}=0.023)$ and $\mathrm{HCO}_{3}^{-}(\mathrm{r}=0.58$, $\mathrm{p}=0.030)$, but not $\mathrm{SaO}_{2}(\mathrm{r}=-0.48, \mathrm{p}=0.08)$. Furthermore, $\mathrm{a}$ negative correlation between $\Delta \mathrm{PavCO}_{2}$ and $\Delta \mathrm{V}_{\mathrm{E}}$ was found $(\mathrm{r}=$ $-0.60, \mathrm{p}=0.024)$, but not $\Delta \mathrm{V}_{\mathrm{D}} / \mathrm{V}_{\mathrm{T}}(\mathrm{r}=0.42, \mathrm{p}=0.18)$.

There was no significant change in $\mathrm{V}_{\mathrm{E}}$ when breathing $\mathrm{F}_{\mathrm{i}} \mathrm{O}_{2}$ 0.28 (table 2). In contrast, during $\mathrm{F}_{\mathrm{i}} \mathrm{O}_{2} 0.50$ a consistent fall in $\mathrm{V}_{\mathrm{E}}$ of $1.2 \pm 2.1 \mathrm{~L} / \mathrm{min}(12 \pm 22 \%)$ below baseline occurred within 5 min (figure 3). Thereafter, a varying recovery in $V_{E}$ was observed (figure 4C), such that after $20 \mathrm{~min} \mathrm{~V}_{\mathrm{E}}$ remained below baseline in six participants, returned to baseline in four participants and exceeded baseline $\mathrm{V}_{\mathrm{E}}$ by $>5 \%$ in four participants. After $20 \mathrm{~min}$, group mean $\mathrm{V}_{\mathrm{E}}$ was $3 \pm 20 \%$ below baseline, which became non-significant after adjustment (raw $\mathrm{p}=0.014$, adj.p $=0.224$ ). Decreases in $V_{E}$ were attributable to significant falls in $V_{T}$, as RR was unchanged.
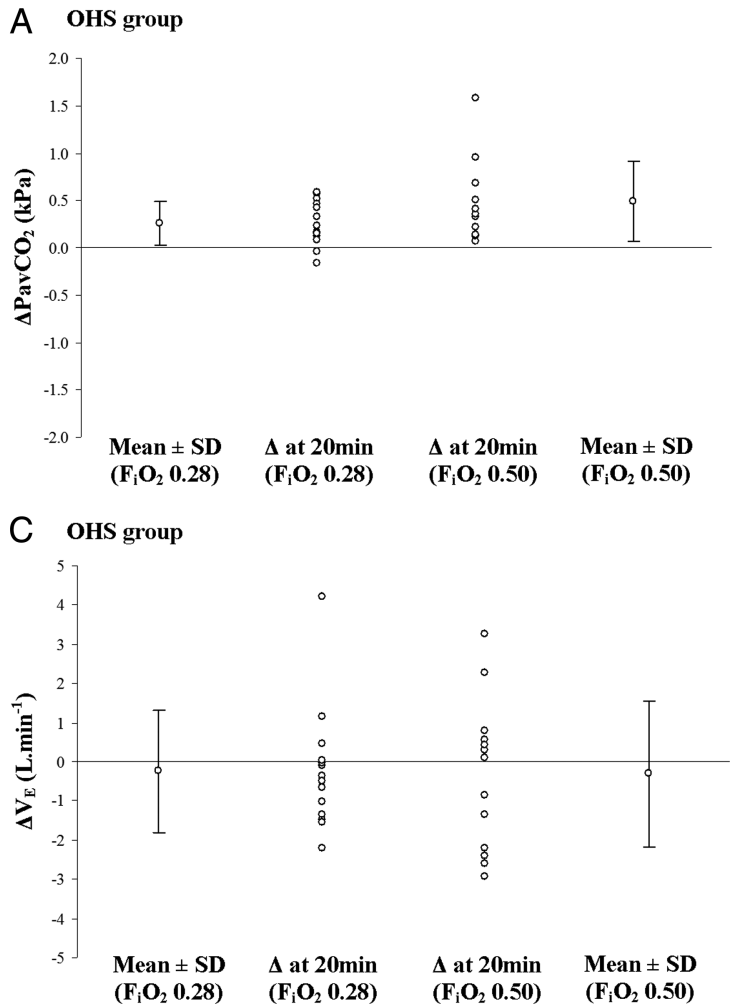

During $\mathrm{F}_{\mathrm{i}} \mathrm{O}_{2} 0.28$ and $0.50, \mathrm{~V}_{\mathrm{D}} / \mathrm{V}_{\mathrm{T}}$ increased by $1 \pm 5 \%$ and $3 \pm 3 \%$, respectively (adj.p $=0.012$ ), in the absence of significant changes in $\mathrm{V}_{\mathrm{D}}$ phys.

\section{Control group: responses to supplemental oxygen}

Among the controls, there were no significant changes in $\mathrm{PavCO}_{2}$ or $\mathrm{pH}$ during either $\mathrm{F}_{\mathrm{i}} \mathrm{O}_{2}$ (table 2, figure 3), and no significant differences for $\mathrm{PavCO}_{2}$ between concentrations. During $\mathrm{F}_{\mathrm{i}} \mathrm{O}_{2} 0.28$ there were no significant changes in $\mathrm{V}_{\mathrm{E}}, \mathrm{V}_{\mathrm{T}}$ or $\mathrm{RR}$. However, breathing $\mathrm{F}_{\mathrm{i}} \mathrm{O}_{2} \quad 0.50$ increased $\mathrm{V}_{\mathrm{E}}$ by $15 \pm 11 \%$ after $20 \mathrm{~min}$ (adj.p=0.019), due to a slight, non-significant increase in RR (raw p=0.01, adj.p $=0.170$ ).

Significant increases in $\mathrm{V}_{\mathrm{D}} / \mathrm{V}_{\mathrm{T}}$ of $1 \pm 3 \%$ and $4 \pm 3 \%$ were observed during $\mathrm{F}_{\mathrm{i}} \mathrm{O}_{2} 0.28$ and 0.50 respectively (adj.p=0.012). This was accompanied by small rises in $\mathrm{V}_{\mathrm{D}}$ phys which became non-significant after adjustment (raw p <0.001, adj.p=0.085).
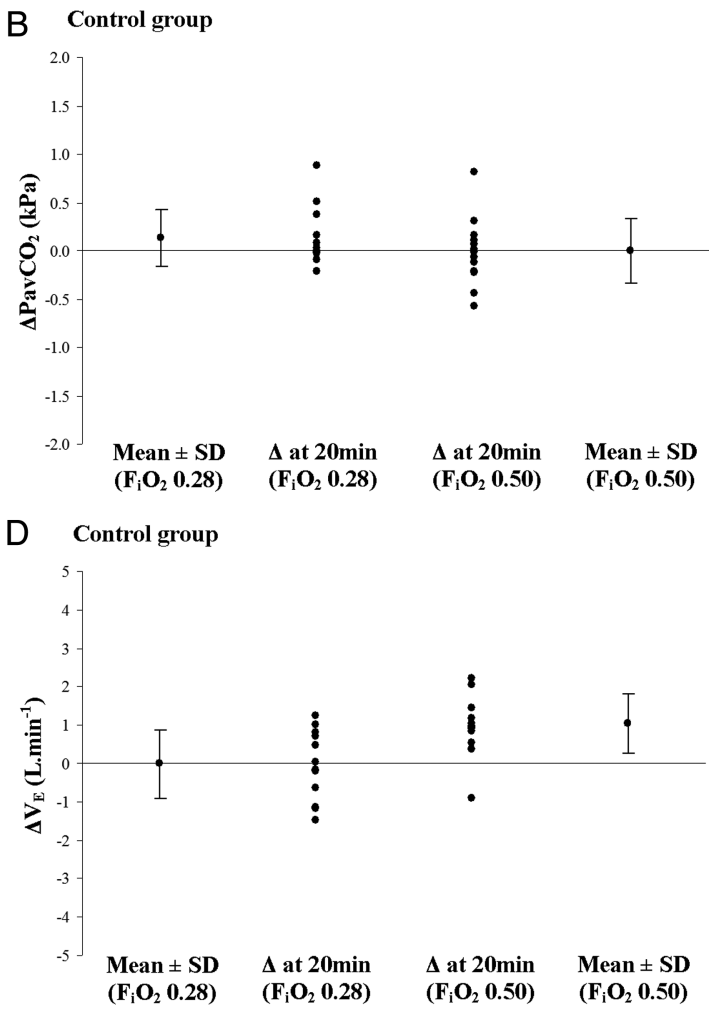

Figure 4 Individual and group responses to supplemental oxygen concentration $\left(\mathrm{F}_{\mathrm{i}} \mathrm{O}_{2}\right) 0.28$ and 0.50 for $\mathrm{OHS}$ group $(\mathrm{A}$ and $\mathrm{C})$ and control group $(A$ and $D)$, showing change in arterialised-venous carbon dioxide from room air baseline $\left(\triangle P a v C O_{2}\right)(A$ and $B)$, and change in minute ventilation from room air baseline $\left(V_{E}\right)(C$ and $D)$. Each figure includes individual changes at 20 min for $F_{i} O_{2} 0.28$ and group mean $\pm S D$ on the left, and individual changes at 20 min for $\mathrm{F}_{\mathrm{i}} \mathrm{O}_{2} 0.50$ and group mean $\pm \mathrm{SD}$ on the right. $\mathrm{OHS}$, obesity hypoventilation syndrome. 


\section{DISCUSSION}

To our knowledge, this is the first study to investigate the effects of clinically relevant, moderate concentrations of supplemental oxygen on $\mathrm{PCO}_{2}$ and $\mathrm{pH}, \mathrm{V}_{\mathrm{D}} / \mathrm{V}_{\mathrm{T}}$ and $\mathrm{V}_{\mathrm{E}}$ and its determinants among people with OHS. In OHS, hyperoxia induced by breathing $\mathrm{F}_{\mathrm{i}} \mathrm{O}_{2} \quad 0.28$ and $\mathrm{F}_{\mathrm{i}} \mathrm{O}_{2} \quad 0.50$ caused significant rises in $\mathrm{PavCO}_{2}$. Accordingly, $\mathrm{pH}$ decreased, resulting in acidaemia during $\mathrm{F}_{\mathrm{i}} \mathrm{O}_{2}$ 0.50. Breathing $\mathrm{F}_{\mathrm{i}} \mathrm{O}_{2} \quad 0.50$ was accompanied by hypoventilation and increases in $\mathrm{V}_{\mathrm{D}} / \mathrm{V}_{\mathrm{T}}$. However, changes in $\mathrm{V}_{\mathrm{E}}$ were the key determinant of $\mathrm{PavCO}_{2}$ rises. Breathing $\mathrm{F}_{\mathrm{i}} \mathrm{O}_{2} 0.50$ also increased $\mathrm{V}_{\mathrm{D}} / \mathrm{V}_{\mathrm{T}}$ in the control group, but controls maintained a stable $\mathrm{PavCO}_{2}$ and $\mathrm{pH}$ through a $15 \%$ increase in $\mathrm{V}_{\mathrm{E}}$. The findings of the present study bring into question the safety of moderate concentrations of supplemental oxygen among patients with untreated OHS and provide evidence to substantiate current clinical guidelines on oxygen prescription. ${ }^{6}$

Among participants with OHS, hyperoxia induced by supplemental oxygen significantly worsened hypercapnia and lowered $\mathrm{pH}$. In an earlier study, breathing $100 \%$ oxygen increased transcutaneous $\mathrm{PCO}_{2}$ in obesity-associated hypercapnia, ${ }^{7}$ but the clinical relevance of this report was unclear because $\mathrm{pH}$ was not measured and transcutaneous $\mathrm{PCO}_{2}$ was used, inherently adding potential errors to $\mathrm{PCO}_{2}$ measures and preventing a definitive diagnosis of OHS. ${ }^{5}$ The present study provided further physiological detail and insight into the clinical relevance of the effects of hyperoxia in OHS. Although the minimal important difference for $\mathrm{PCO}_{2}$ in OHS has not been defined, in the present study the rise in $\mathrm{PavCO}_{2}$ during $\mathrm{F}_{\mathrm{i}} \mathrm{O}_{2} 0.50(0.5 \pm 04 \mathrm{kPa})$ was considered clinically significant because it induced acidaemia. In patients with COPD, hyperoxia-related acidaemia is associated with higher in-hospital morbidity, ${ }^{9}$ and this may apply to acutely unwell patients with OHS ${ }^{2}{ }^{8}$ but has not been addressed. Therefore, in light of the results of the present study, the influence of supplemental oxygen usage on morbidity, mortality and healthcare utilisation in people with OHS requires investigation.

\section{Ventilatory responses to hyperoxia Controls}

Interestingly, $\mathrm{V}_{\mathrm{D}} / \mathrm{V}_{\mathrm{T}}$ increased among the control group with both oxygen concentrations, with rises of the same magnitude as those of the OHS group (figure 3). Despite this, $\mathrm{PavCO}_{2}$ and $\mathrm{pH}$ remained relatively stable, albeit with some individual variation (figure 4B). During $\mathrm{F}_{\mathrm{i}} \mathrm{O}_{2}$ 0.50, stable $\mathrm{PavCO}_{2}$ levels were achieved by a $15 \pm 11 \%$ increase in $\mathrm{V}_{\mathrm{E}}$. This is consistent with previous observations among healthy controls breathing 100\% $\mathrm{O}_{2}{ }^{20-23}$ and is indicative of normal ventilatory control. Hyperoxic hyperventilation in healthy individuals is usually preceded by a fall in $\mathrm{V}_{\mathrm{E}}(\sim 5-12 \%)$ within the first $30 \mathrm{~s}$ to $2 \mathrm{~min}$ of breathing $100 \%$ oxygen via inhibition of the peripheral chemoreceptors, which are tonically active within a normal $\mathrm{PaO}_{2}$ range. ${ }^{20} 2123$ However, the washout time of circuit gases prevented this being captured in the present study. Quickly thereafter, $\mathrm{V}_{\mathrm{E}}$ increases above baseline due to transient increases in $\mathrm{PaCO}_{2}$ from initial hypoventilation, ${ }^{22}$ the Haldane effect, ${ }^{22}$ increases in $\mathrm{V}_{\mathrm{D}} / \mathrm{V}_{\mathrm{T}}$ and possibly in part through direct stimulation of chemoreceptors. ${ }^{22}$

\section{Obesity hypoventilation syndrome}

Participants with OHS also experienced increases in $V_{D} / V_{T}$ during hyperoxia. However, unlike the controls, breathing $\mathrm{F}_{\mathrm{i}} \mathrm{O}_{2}$ 0.50 was invariably characterised by marked hypoventilation for the first 5-10 min, followed by a partial recovery in $V_{E}$. The recovery of $\mathrm{V}_{\mathrm{E}}$ was usually insufficient to overcome the increase in $\mathrm{V}_{\mathrm{D}} / \mathrm{V}_{\mathrm{T}}$, hence $\mathrm{PavCO}_{2}$ was elevated after 20 min of $\mathrm{F}_{\mathrm{i}} \mathrm{O}_{2} 0.50$ in most participants (figure 4). There was a negative correlation between $\Delta \mathrm{V}_{\mathrm{E}}$ and $\Delta \mathrm{PavCO}_{2}$, but $\Delta \mathrm{V}_{\mathrm{D}} / \mathrm{V}_{\mathrm{T}}$ was not associated with $\Delta \mathrm{PavCO}_{2}$. These results suggest that the $\mathrm{PavCO}_{2}$ rises observed amongst OHS participants were largely a result of inadequate ventilatory control. Impaired respiratory chemosensitivity is a common feature of $\mathrm{OHS}^{24-26}$ and may explain why the initial decrease in $\mathrm{V}_{\mathrm{E}}$ during hyperoxia was of a larger magnitude, with much slower recovery, than that reported in controls. ${ }^{21} 23$ Blunted hypercapnic ventilatory responses could also explain why an elevation of $\mathrm{PavCO}_{2}$ at $20 \mathrm{~min}$ was tolerated by most participants. However, hypercapnic ventilatory responses are highly variable between individuals with OHS and are sometimes within the normal range in patients with mild hypercapnia, ${ }^{24-26}$ which may explain the variability in ventilatory responses to hyperoxia in the OHS group. We did not test ventilatory responses and are therefore unable to confirm their role in the changes in $\mathrm{PavCO}_{2}$ observed during hyperoxia.

\section{Factors potentially influencing $\mathrm{V}_{\mathrm{D}} / \mathrm{V}_{\mathrm{T}}$ in controls and $\mathrm{OHS}$}

In both groups, $\mathrm{V}_{\mathrm{D}} / \mathrm{V}_{\mathrm{T}}$ increased significantly during hyperoxia, although the contribution of this small change towards potential $\mathrm{PavCO}_{2}$ rises is uncertain. Increased $\mathrm{V}_{\mathrm{D}} / \mathrm{V}_{\mathrm{T}}$ could arise from an increase in $\mathrm{V}_{\mathrm{D}}$ phys, a decrease in $\mathrm{V}_{\mathrm{T}}$ or both. In studies measuring $\mathrm{V} / \mathrm{Q}$ distributions in healthy controls, ${ }^{27}$ and patients with OHS, ${ }^{28}$ breathing $100 \%$ oxygen has been shown to increase perfusion to poorly ventilated regions of lung through the release of local hypoxic vascoconstriction. ${ }^{27}$ This results in underperfusion of well ventilated regions, thereby increasing $\mathrm{V}_{\text {D phys. }}{ }^{27}$ This mechanism is plausible among the control group, in whom a small increase in $\mathrm{V}_{\mathrm{D}}$ phys was observed during $\mathrm{F}_{\mathrm{i}} \mathrm{O}_{2}$ 0.50. However, this change became non-significant after statistical adjustment. In contrast, no change was observed in $\mathrm{V}_{\mathrm{D}}$ phys among the OHS group. It has been shown that $\mathrm{V}_{\mathrm{D}}$ phys has a proportional relationship with $\mathrm{V}_{\mathrm{T}}{ }^{29}{ }^{30}$ Therefore in OHS participants, increases in $\mathrm{V}_{\mathrm{D}}$ phys occurring due to increased $\mathrm{V} /$ $\mathrm{Q}$ inequality may have been offset by the concomitant fall in $\mathrm{V}_{\mathrm{T}}$. Given the lack of increase in $\mathrm{V}_{\mathrm{D}}$ phys during hyperoxia among OHS participants, rises in $\mathrm{V}_{\mathrm{D}} / \mathrm{V}_{\mathrm{T}}$ are largely attributable to the reduction in $\mathrm{V}_{\mathrm{E}}$ (via the reduction in $\mathrm{V}_{\mathrm{T}}$ ), which is consistent with previous observations in patients with obesity-associated hypercapnia whilst breathing 100\% oxygen. ${ }^{7}$ However, we did not perform invasive $\mathrm{V} / \mathrm{Q}$ measures and therefore were unable to characterise the complex interactions between pulmonary ventilation and perfusion, gas exchange and breathing pattern when patients were breathing moderate oxygen concentrations.

\section{Clinical implications}

Clinically important differences between the two concentrations of oxygen were observed in the present study, that is, hyperoxia induced by $\mathrm{F}_{\mathrm{i}} \mathrm{O}_{2} \quad 0.28$ caused minimal changes in $\mathrm{pH}$ or $\mathrm{V}_{\mathrm{E}}$, while $\mathrm{F}_{\mathrm{i}} \mathrm{O}_{2} \quad 0.50$ caused hypoventilation and acidaemia. Furthermore, compared with responses to $\mathrm{F}_{\mathrm{i}} \mathrm{O}_{2} \quad 0.50$ in our OHS participants, even more marked changes in $\mathrm{PCO}_{2}$ and $\mathrm{V}_{\mathrm{E}}$ occurred during 100\% oxygen in obesity-associated hypercapnia. ${ }^{7}$ The mechanisms by which hyperoxia induces hypoventilation in OHS remain unclear. However, these findings suggest that a greater degree of respiratory depression occurs with higher oxygen concentrations. Therefore, in stable OHS, hyperoxia caused by breathing $\mathrm{F}_{\mathrm{i}} \mathrm{O}_{2} 0.28$ may be less harmful than $\mathrm{F}_{\mathrm{i}} \mathrm{O}_{2} 0.50$ or 1.0 .

Substantial inter-individual variability in $\Delta \mathrm{PavCO}_{2}$ during hyperoxia was evident among the OHS group; as has been reported in obesity-associated hypercapnia ${ }^{7}$ and COPD. ${ }^{16}$ 
Therefore it would be clinically useful to identify features that may predict adverse responses to hyperoxia. Strong associations between $\Delta \mathrm{PavCO}_{2}$ and baseline $\mathrm{PaCO}_{2}$ and $\mathrm{HCO}_{3}^{-}$were observed, suggesting that patients with OHS and severe hypercapnia (and associated elevated $\mathrm{HCO}_{3}^{-}$levels) are more likely to develop worsening hypercapnia during hyperoxia. This is plausible, given the tendency for people with OHS and a higher $\mathrm{PaCO}_{2}$ to have lower hypercapnic ventilatory responses than those with lower $\mathrm{PaCO}_{2} \cdot{ }^{24-26}$ Elevated $\mathrm{HCO}_{3}^{-}$may also directly blunt hypercapnic ventilatory responses in OHS, through an increased acid-buffering capacity. ${ }^{31} 32$ Previous data also suggest that people with more severe hypoxaemia may experience larger $\mathrm{PCO}_{2}$ rises during hyperoxia, ${ }^{7}$ although this was not evident amongst our mildly hypoxaemic group.

Participants in the present study were clinically stable, with mild hypercapnia and hypoxaemia. Therefore our findings probably underestimate the dangers of hyperoxia in people with OHS with severe hypercapnia and/or acute cardiorespiratory illness. The effects of supplemental oxygen in this population warrant further investigation. Even so, the findings of the present study highlight the potential risks associated with the administration of moderate concentrations of supplemental oxygen among people with OHS. These findings also provide an evidence base for current guidelines, ${ }^{6}$ which recommend that in OHS, supplemental oxygen should be titrated to maintain $\mathrm{SpO}_{2}$ 88-92\%, thereby avoiding hyperoxia and hypoxaemia. Oxygen supplementation should also include close monitoring and periodic reassessment of ABGs. ${ }^{6}$

\section{Limitations}

In this study, we documented acute responses to breathing supplemental oxygen for $20 \mathrm{~min}$. Based on the time course of $\mathrm{PavCO}_{2}$ (figure 3), a plateau in $\mathrm{PavCO}_{2}$ occurred after $10 \mathrm{~min}$ of breathing oxygen. However, due to the large capacity of the body for $\mathrm{CO}_{2}$ storage, $\mathrm{CO}_{2}$ equilibrium is not usually achieved until 20-30 min after a change in ventilation ${ }^{33}$ and therefore participants may not have reached $\mathrm{CO}_{2}$ steady state. In clinical practice, patients are usually treated with supplemental oxygen for extended periods. Hence, the effects of longer periods of supplemental oxygen require evaluation to further strengthen clinical practice guidelines.

\section{CONCLUSION}

Among people with mild, stable untreated OHS, breathing moderate concentrations of supplemental oxygen increased $\mathrm{PavCO}_{2}$, sufficient to induce acidaemia during $\mathrm{F}_{\mathrm{i}} \mathrm{O}_{2}$ 0.50. These findings highlight the need for caution during supplemental oxygen administration among people with OHS and support current clinical guidelines which recommend targeting an $\mathrm{SpO}_{2}$ range and monitoring of ABGs during supplemental oxygen administration.

\section{Acknowledgements The authors thank each of the study participants, and Associate Professor Brendon Yee for his assistance.}

Contributors $\mathrm{CAH}$ : contributed to design and implementation of the study, data collection, statistical analysis, preparation and editing of manuscript; ARH, LJM, CM: contributed to design and implementation of the study, data collection, and editing of manuscript; GNW: contributed to original concept and design of the study, and editing of manuscript; GU: designed and built breathing circuit and data acquisition/ analysis programmes, and contributed to study design, data analysis and editing of manuscript; DF: contributed to design and implementation of study, data collection and editing of the manuscript; DAB: contributed to design of the study, and editing of manuscript; AJP: contributed to design and implementation of the study, and editing of manuscript.

Funding The study was supported by a Cardiorespiratory Physiotherapy Australia Research Grant from the Physiotherapy Research Foundation (grant no. T08-CAR/JN016).
Competing interests AJP received fees for lectures from ResMed, Asia Pacific and Philips Respironics, Australia. She has also received a grant to evaluate therapy in obesity hypoventilation syndrome from the ResMed Foundation. GNW has previously been a consultant to ResMed, Asia Pacific. He has received fees for lectures from ResMed, Asia Pacific. All other authors have no actual or potential competing interests to disclose.

Ethics approval Respective ethics committees of Royal Prince Alfred Hospital and The University of Sydney, Sydney Australia.

Provenance and peer review Not commissioned; externally peer reviewed.

\section{REFERENCES}

1 Nowbar S, Burkart KM, Gonzales R, et al. Obesity-associated hypoventilation in hospitalized patients: prevalence, effects, and outcome. Am J Med 2004 116:1-7.

2 Budweiser S, Riedl SG, Jorres RA, et al. Mortality and prognostic factors in patients with obesity-hypoventilation syndrome undergoing noninvasive ventilation. $J$ Intern Med 2007;261:375-83.

3 Berg G, Delaive K, Manfreda J, et al. The use of health-care resources in obesity-hypoventilation syndrome. Chest 2001;120:377-83.

4 Jennum $\mathrm{P}$, Kjellberg J. Health, social and economical consequences of sleep-disordered breathing: a controlled national study. Thorax 2011; 66:560-6.

5 Mokhlesi B. Obesity hypoventilation syndrome: a state-of-the-art review. Respir Care 2010;55:1347-65.

6 O'Driscoll BR, Howard LS, Davison AG. BTS guideline for emergency oxygen use in adult patients. Thorax 2008;63(Suppl 6):vi1-68.

7 Wijesinghe $M$, Williams $M$, Perrin $K$, et al. The effect of supplemental oxygen on hypercapnia in subjects with obesity-associated hypoventilation: a randomized cross-over clinical study. Chest 2011;139:1018-24.

8 Carrillo A, Ferrer M, Gonzalez-Diaz G, et al. Noninvasive ventilation in acute hypercapnic respiratory failure caused by obesity hypoventilation syndrome and chronic obstructive pulmonary disease. Am J Respir Crit Care Med 2012; 186:1279-85.

9 Plant PK, Owen JL, Elliott MW. One year period prevalence study of respiratory acidosis in acute exacerbations of COPD: implications for the provision of non-invasive ventilation and oxygen administration. Thorax 2000; 55:550-4.

10 Austin MA, Wills KE, Blizzard L, et al. Effect of high flow oxygen on mortality in chronic obstructive pulmonary disease patients in prehospital setting: randomised controlled trial. BMJ 2010:341:c5462.

11 Joosten SA, Koh MS, Bu X, et al. The effects of oxygen therapy in patients presenting to an emergency department with exacerbation of chronic obstructive pulmonary disease. Med J Aust 2007;186:235-8.

12 Dick CR, Liu Z, Sassoon CS, et al. $\mathrm{O}_{2}$-induced change in ventilation and ventilatory drive in COPD. Am J Respir Crit Care Med 1997;155:609-14.

13 Aubier M, Murciano D, Milic-Emili J, et al. Effects of the administration of $\mathrm{O}_{2}$ on ventilation and blood gases in patients with chronic obstructive pulmonary disease during acute respiratory failure. Am Rev Respir Dis 1980;122:747-54.

14 Sassoon CS, Hassell KT, Mahutte CK. Hyperoxic-induced hypercapnia in stable chronic obstructive pulmonary disease. Am Rev Respir Dis 1987; 135:907-11.

15 Dunn WF, Nelson SB, Hubmayr RD. Oxygen-induced hypercarbia in obstructive pulmonary disease. Am Rev Respir Dis 1991;144:526-30.

16 Robinson TD, Freiberg DB, Regnis JA, et al. The role of hypoventilation and ventilation-perfusion redistribution in oxygen-induced hypercapnia during acute exacerbations of chronic obstructive pulmonary disease. Am J Respir Crit Care Med 2000;161:1524-9.

17 Hollier CA, Maxwell LJ, Harmer AR, et al. Validity of arterialised-venous $\mathrm{PCO}_{2}, \mathrm{pH}$ and bicarbonate in obesity hypoventilation syndrome. Respir Physiol Neurobiol 2013:188:165-71.

18 Tang Y, Turner MJ, Baker AB. A new equal area method to calculate and represent physiologic, anatomical, and alveolar dead spaces. Anesthesiology 2006; 104:696-700.

19 Holm S. A simple sequentially rejective multiple test procedure. Scand Stat Theory Appl 1979;6:65-70.

20 Marczak M, Pokorski M. Oxygen breathing and ventilation. J Physiol Pharmacol 2003:55:127-34

21 Downes JJ, Lambertsen CJ. Dynamic characteristics of ventilatory depression in man on abrupt administration of oxygen. J App/ Physiol 1966; 21:447-53.

22 Becker HF, Polo 0, McNamara SG, et al. Effect of different levels of hyperoxia on breathing in healthy subjects. J Appl Physiol 1996;81:1683-90.

23 Dripps RD, Comroe JH. The effect of the inhalation of high and low oxygen concentrations on respiration, pulse rate, ballisto-cardiogram and arterial oxygen saturation (oximeter) of normal individuals. Am J Physiol 1947; 149:277-91. 
24 de Lucas-Ramos P, de Miguel-Diez J, Santacruz-Siminiani A, et al. Benefits at 1 year of nocturnal intermittent positive pressure ventilation in patients with obesity-hypoventilation syndrome. Respir Med 2004:98:961-7.

25 Zwillich CW, Sutton FD, Pierson DJ, et al. Decreased hypoxic ventilatory drive in the obesity-hypoventilation syndrome. Am J Med 1975;59:343-8.

26 Chouri-Pontarollo N, Borel JC, Tamisier R, et al. Impaired objective daytime vigilance in obesity-hypoventilation syndrome: impact of noninvasive ventilation. Chest 2007;131:148-55.

27 Wagner PD, Laravuso RB, Uhl RR, et al. Continuous distributions of ventilation-perfusion ratios in normal subjects breathing air and 100 per cent $\mathrm{O}_{2}$. J Clin Invest 1974;54:54-68.

28 Barrera F, Hillyer P, Ascanio G, et al. The distribution of ventilation, diffusion, and blood flow in obese patients with normal and abnormal blood gases. Am Rev Respir Dis 1973;108:819-30.
29 Fletcher $\mathrm{R}$, Jonson B. Deadspace and the single breath test for carbon dioxide during anaesthesia and artificial ventilation. Effects of tidal volume and frequency of respiration. Br J Anaesth 1984;56:109-19.

30 Chakrabarti MK, Gordon G, Whitwam JG. Relationship between tidal volume and deadspace during high frequency ventilation. Br J Anaesth 1986:

58:11-17.

31 Goldring RM, Turino GM, Heinemann HO. Respiratory-renal adjustments in chronic hypercapnia in man. Extracellular bicarbonate concentration and the regulation of ventilation. Am J Med 1971;51:772-84.

32 Raurich JM, Rialp G, Ibanez J, et al. Hypercapnic respiratory failure in obesity-hypoventilation syndrome: $\mathrm{CO}_{2}$ response and acetazolamide treatment effects. Respir Care 2010;55:1442-8.

33 Jones NL, Jurkowski JE. Body carbon dioxide storage capacity in exercise. J App/ Physiol 1979:46:811-15. 